\section{Realidade versus Necessidades da Pesquisa Turística no Brasil}

\section{Mirian Rejowski}

RESUMO: Este artigo enfoca a pesquisa científica em Turismo no Brasil, procurando conciliar as preocupações acadêmicas com a prática empresarial. Baseia-se na revisão da literatura sobre pesquisa científica e empreendimentos turísticos, na análise documental das teses brasileiras e nas opiniões de pesquisadores acadêmicos, em presários e profissionais, obtidas através da aplicação de questionários e entrevistas em São Paulo, Rio de Janeiro e Salvador. Sintetiza os principais resultados sobre a realidade e as necessidades da pesquisa turística no Brasil, apresenta propostas para a valorização da pesquisa e do pesquisador turístico, e indica prioridades temáticas para futuras pesquisas na área relacionadas às forças globais emergentes que afetarão a sociedade no próximo Milênio.

PALAVRAS-CHAVE: Turismo e pesquisa; pesquisa científica; realidade; necessidades; propostas; prioridades temáticas; Brasil.

ABSTRACT: This article emphasizes the scientific tourism research in Brazil, conciliting the academics concerns with the practical enterprising activities. It was based on scientific research lliterature and touristic undertakings revisions; indocumental thesis analysis and in the opinions of academic researchers, tourism entrepeneurs and area professionals. The information related in this study was taken through questionnaire apllications and personal enterviews realized in Säo Paulo, Rio de Janeiro e Salva-

1. Bacharel em Turismo, Mestre e Doutora em Ciências da Comunicação pela Escola de Comunicaçōes e Artes da Universidade de São Paulo(ECA-USP). Livre Docenteem Teoria do Turismo e do Lazer pelaECA-USP. Professora de cursos de graduação e pós-graduação em Turismo.

End.: ECA-USP - Depto. de Relaçōes Públicas, Propaganda e Turismo - Cidade Universitária, Av. Prof. Lúcio M. Rodrigues, 443 - Butantã - 04515-030 -São Paulo - SP - Brasil. Fax: (55-11-8184331)-E-mail: mirwski@usp.br dor. It introduces proposals for the valorization of scientific research and touristic researchers, and it indicates for thematics priorities for the future works research related to the emergent global strength, which will impact our society in the next Millenium.

KEYWORDS: Tourism and research; pesquisa cientifica reality; needs; proposals; thematics priorities; Brazil.

\section{Introduçāo}

Este trabalho enfoca a realidade da ocorrência das pesquisas turísticas e quais as suas principais necessidades no Brasil, unindo preocupações acadêmicas a preocupações empresariais, com o objetivo de identificar os fatores que possam contribuir para a melhoria das pesquisas científicas que irão embasar o desenvolvimento do Turismo Brasileiro no próximo Milênio. Apresenta, na verdade, os resultados mais significativos de umestudo exploratório-descritivo desenvolvido de 1995 a 1997, sobre a Realidade Turística nas Pesquisas Científicas ${ }^{2}$, referindo-se a três momentos de pesquisa, cujos dados foram colhidos em três universos:

- Teses em Turismo no Brasil: pcsquisa documental envolvendo levantamento, análise e sistematização de dados de 102 teses brasileiras sobre Turismo, de 1973 a 1995, onde se utilizou ficha técnica e montagem de uma base de dados ("software" Microisis);

- Pesquisa Turística no Brasil sob a Ótica dos Pesquisadores: pesquisa de opinião junto a 42 pesquisadores turísticos em São Paulo, Rio de Janeiro e Salvador, enfocando a realidade e as necessidades da pesquisa turística no Brasil, com base em questionário;

- Pesquisador e Pesquisa Turística no Brasil sob a Ótica dos Empresários e Profissionais: pesquisa de opinião junto a 21 empresários e/ou profissionais de empresas, entidades e órgãos de Turismo em São Paulo, Rio de Janeiro e Salvador, enfocando a parceira pesquisador/empresário, assim como as necessidades e prioridades da pesquisa turística no Brasil, com a utilização de entrevistas semiestruturadas.

Contrapondo a situação atual com as necessidades da pesquisa turística no Brasil aborda-se o cenário mundial e nacional, a produção científica (teses), a visão dos pesquisadores e dos empresários e profissionais. Da comparação e discussão dos dados obtidos, surgem propostas de valorização tanto da pesquisa quanto do

2. Esse estudo foi apresentado como tese de livre docência para obtenção de título acadêmico na especialidade "Teoria do Turismo e do Lazer", junto ao Departamento de Relaçoes Públicas, Propaganda e Turismo da ECA-USP em dezembro de 1997 (Rejowski, 1997). 
pesquisador turístico, além de uma relação de prioridades temáticas da pesquisa turística no Brasil.

\section{Cenário Mundial e Nacional}

O Turismo assume, a partir da década de cinqüenta uma importância no âmbito das Ciências Humanas e Sociais. As pesquisas de conteúdo turístico têm se expandido nas várias áreas do conhecimento. Com isso há evolução para a formação de estudos científicos multi e interdisciplinares, visando a atividade turística. A pobreza e à pouca seriedade, o estudo do Turismo vai cedendo lugar à abordagem técnico-científica que, como tal, vem sendo tratada em países e regiões onde o Turismo tem prioridade econômica, social e política.

A comunidade acadêmica no Brasil encontra-se atualizada e bastante familiarizada com os avanços internacionais. No entanto, há fragilidade na organização e relacionamento dos pesquisadores, no sentido de haver pouca comunicação entre os mesmos. Por outro lado, há sedimentação e posicionamento do Turismo como área de estudo e pesquisa no âmbito da universidade brasileira.

Nesse contexto mundial, situam-se associações científicas, como a Associação Internacional de Experts Científicos em Turismo (AIEST) e a Academia Internacional para o Estudo do Turismo (IAST), realizam-se eventos científicos para a discussão e análise de temas específicos do Turismo, e editam-se publicações que já abordam o estado-da-arte dessa área de conhecimento, indicando, portanto, uma sistematização da mesma, onde a pesquisa científica tem papel fundamental.

A situação atual da pesquisa turística no Brasil indica que tal processo encontra-se no seu estágio inicial. Apesar do número significativo de cursos de graduação de Turismo e Hotelaria (acima de cinqüenta), poucos são os que privilegiam a pesquisa científica. A pesquisa acadêmica de pós-graduação strictu sensu apresenta-se esparsa e fragmentada até o início dos anos 90, a partir de quando esse panorama começa a alterar-se pelo acesso à tecnologia da informática(Internet) A bilbiografia publicada no País ainda é pequena, mas já mostra indícios de aproximação à pesquisa científica - atualmente a maioria dos autores de livros editados sobre Turismo são pesquisadores e/ou docentes dessa área. De meados dos anos 70 até o início dos anos 90, os poucos eventos, com raras exceções, não privilegiam a pesquisa e seus resultados. A partir de 1993, no entanto, realizam-se eventos de caráter eminentemente científico, com ênfase na apresentação de relatos de pesquisa. A não-existência de um centro de documentação e de uma associação científica brasileira na área, que promova o intercâmbio para e entre os pesquisadores e a disseminação dos resultados de suas pesquisas, indica a pouca organização e sistematização da documentação e da comunidade científica em Turismo.

Delineou-se, neste trabalho, tendências que alterarão o estudo do Turismo no próximo Milênio. Novos horizontes e novas realidades levarão a considerar o ambiente como centro de preocupações, as alterações demográficas, os segmentos de demanda em ascensão, a alteração dos sistemas de valores e a procura da maior qualidade em produtos e serviços modificando as ofertas.

Nesse cenário o Turismo emerge como importante atividade econômica em expansão até o final do século. É preciso, porém, que os países em desenvolvimento implantem reformas políticas e econômicas, e se adaptem ao fenômeno da globalização. Dessa maneira aumenta a necessidade de pesquisas básicas e aplicadas, e de estudos que façam prognósticos para apoiar o planejamento estratégico do Turismo em seu aspecto global, em países que estão se posicionando no cenário mundial.

É preciso lembrar que os financiamentos internacionais em geral dirigem-se aos países e não às empresas, apoiando basicamente o setor público com financiamento a projetos de infra-estrutura básica. Os pesquisadores devem ter ciência disto.

O setor privado no Brasil conta com dotações do governo federal, linhas de crédito operadas pelo BNDES - Banco Nacional de Desenvolvimento, bancos estaduais e agências de fomento. O FUNGETUR - Fundo Geral de Turismo, no período de 1990 a 1995, atendeu basicamente projetos relacionados a meios de hospedagem. OBNDES nesse mesmo período enviou recursos destinados principalmente à expansão de hotéis com restaurantes. Assim, a ênfase no período $1990 \mathrm{a}$ 1995 foi de apoio à hotelaria, mas com um volume pouco expressivo de recursos se comparado a outros setores econômicos (industriais).

Em 1996, nota-se já um crescimento significativo de recursos para projetos de atividades de lazer. Está ocorrendo, na realidade, abertura de novas perspectivas para projetos envolvendo outros setores da estrutura turística, como por exemplo parques temáticos e marinas, que se inserem em uma visão mais ampla e contemporânea do Turismo e das necessidades da demanda turística. Tal fenômeno irá requerer, certamente, pesquisas, estudos e projetos com equipes interdisciplinares.

\section{Produçāo Científica - Teses}

A análise do conjunto de 102 teses sobre Turismo, apresentadas em instituições de ensino superior brasileiras no período de 1973 a 1995, altera parcialmente a configuração exposta em estudo anterior de Rejowski (1993) e confirma que houve aumento quantitativo e qualitativo das teses na década de 90 .

As teses concentram-se com maioria significativa em São Paulo, seguindose Florianópolis e Rio de Janeiro. Como já verificado, a maioria da produção é de responsabilidade de instituições públicas, confirmando o pouco engajamento das instituições privadas na pesquisa.

Em ordem decrescente, a começar em 1973 com a Administração, veio depois a Economia e a Geografia. A Escola de Comunicações e Artes da Universidade de São Paulo, tendo iniciado seu curso de Turismo no segundo semestre de 1973, só começou a apresentar produção científica na área a partir de 1980. 
Atualmente as três principais áreas produtoras de pesquisas turísticas continuam a ser a Comunicação, a Administração e a Geografia.

Há crescimento do número de áreas que estão se interessando em estudar Turismo. Novas áreas não-citadas no trabalho anterior de Rejowski (1993), cujo interesse na pesquisa turística é recente, são a Antropologia, a Sociologia, os Sistemas Computacionais, as Ciências Contábeis e o Estudo de Problemas Brasi leiros.

Em relação à temática das teses, há concentração de pesquisas em oferta, desenvolvimento, marketing e planejamento turístico, além de turismo e espaço. Uma das preocupações emergentes no contexto acadêmico científico é o turismo sexual.

Dentre as empresas turísticas estudadas, destacam-se os hotéis e as agências de turismo, empresas tipicamente turísticas. Mas, aqui também surgem novos focos de atenção, como estudos sobre albergues da juventude e residências secundárias no âmbito de meios de hospedagem e não mais da hotelaria de grande porte.

A maioria das teses é centrada em núcleos e regiões litorâneas, de certa forma desvinculada do conhecimento global e comparativo a outras realidades.

As pesquisas exploratórias aparecem em número maior, dada a sua inserção principalmente nas Ciências Humanas e Sociais. Porém é significativo o aumento do número de pesquisas descritivas e explicativas, o que revela um nível de profundidade maior no estudo do Turismo, sendo que as pesquisas explicativas estão gerando modelos, classificações e programas de ação.

Deparou-se com a dificuldade em classificar as pesquisas por seus temas e tipos. Buscou-se configurar, sob o ponto de vista metodológico e conceitual, termos para caracterizar os diversos temas e tipos de estudo. Foi necessário reestruturar a classificação feita no trabalho de doutorado (Rejowski, 1993), pois a antiga caracterização não abrangia todas as 102 teses analisadas. A relação dos temas e dos tipos de estudo é apenas indicativa, devendo ser aperfeiçoada em futuros trabalhos.

\section{Visão dos Pesquisadores}

Os pesquisadores da amostra graduaram-se principalmente em Geografia, Turismo e Economia, e desenvolveram teses no âmbito das Ciências da Comunicação, Administração e Geografia. Na graduação aparecem 16 áreas que foram reduzidas à metade na pós-graduação.

A maioria dos pesquisadores atuavam, na época em que realizaram suas teses, como docentes e provavelmente foram pressionados a seguir a carreira universitária. Por outro lado, o número significativo de pesquisadores alocados em empresas públicas e privadas mostra um outro tipo de pesquisadores mais propensos às pesquisas aplicadas

Atualmente houve uma retração do engajamento em pesquisas dos entrevis- tados em São Paulo e no Rio de Janeiro; e em Salvador, simplesmente uma estagnação. As razões para isso foram ditas como sendo atividade profissional em outra área e falta de tempo.

O interesse do estudo do Turismo altera-se conforme o nível acadêmico da tese. No mestrado é a atuação profissional na área; no doutorado e na livre-docência é o campo de pesquisa novo e promissor.

Os dados em relação às facilidades (apoio e auxílio) para a realização das pesquisas referem-se principalmente a bolsas de estudo isoladas ou associadas a outros auxílios, sendo que no doutorado o pesquisador parece conhecer e acionar mais os apoios associados.

A idéia de que não hábolsas de estudo para a pesquisa turística se revela como falsa. Se o número de bolsistas específicas ao Mestrado de Turismo da Escola de Comunicações e Artes(ECA) é pequeno, é preciso verque as teses são realizadas em outras áreas e unidades fora da ECA que têm maior tradição de captação de bolsas. Portanto, no conjunto, o número de bolsas é significativo.

A maior dificuldade na realização da pesquisa turística, como já visto, é a ausência de dados e de bibliografia especializada. Esta situação também existe no contexto internacional, porém no Brasil é mais acentuada. Outros obstáculos relevantes são o contato com outros pesquisadores e, especificamente na fase de coleta de dados, a colaboração dos elementos da amostra, talvez por desconhecimento da importância das pesquisas.

A média de tempo gasto nas pesquisas de mestrado é 4 anos e 2 meses, e no doutorado 4 anos e 4 meses, o que se considera longo em relação aos níveis internacionais atuais. Já na livre-docência tem-se a média de 2 anos e 8 meses.

O retorno obtido como compensação para o pesquisador foi de satisfação pessoal associada ao progresso profissional.

Existe defasagem entre os temas de interesse pessoal e aqueles que o próprio pesquisador considera prioritários para o desenvolvimento adequado do Turismo no Brasil. Isto porque existe maior facilidade de colher dados sobre determinados assuntos e em certas áreas, e porque o pesquisador se defronta muitas vezes com falta de recursos econômicos para uma pesquisa de maior abrangência e em locais onde é preciso tempo disponível e dinheiro, além da colaboração de órgãos oficiais.

McIntosh, Goeldner e Ritchie (1995) citam novas realidades e novos horizontes de forças globais emergentes. Em comparação com os temas ditos prioritários na pesquisa turística pelos pesquisadores, identificaram-se três que estabelecem essa relação:

- ambiente como centro: preservação ambiental;

- alterações demográficas: turismo alternativo para a terceira idade;

- alteração nos sistemas de valores: turismo cultural. 


\section{Visão dos Empresários e Profissionais}

Como já ocorrido em outras pesquisas, encontraram-se dificuldades na colaboração dos empresários. O retorno em São Paulo foi pouco significativo e no Rio de Janeiro foi nulo.

O empresário é pouco propenso a procurar o pesquisador turístico como fonte para resolução de seus problemas. Sem generalizar, os dados obtidos permitem inferir que os empresários têm visão estereotipada e não confiável do pesquisador turístico e atestar, também, o distanciamento entre eles.

Por outro lado, os empresários em geral têm conhecimento das linhas de crédito para o setor e recebem informações e orientações de entidades e órgãos da área a respeito. No entanto, embora se tenha propagado a abertura de novas linhas de crédito e um maior montante de recursos para a área de Turismo por parte do BNDES em 1996, estes privilegiam os grande empresários em detrimento dos pequenos e médios empresários, os quais não esperam aprovação de seus projetos por esse agente financeiro.

Como em todo financiamento, os agentes se fixam mais nas garantias apresentadas do que na validade da proposta do ponto de vista específico do Turismo. Falta um especialista em Turismo na análise e avaliação de projetos.

Não havendo na realidade uma parceira efetiva entre empresário e pesquisador, é preciso "quebrar" a resistência do empresário quando à validade e aplicação dos dados obtidos pelas pesquisas. Concomitantemente, promover uma imagem mais positiva do pesquisador e da pesquisa turística.

Por outro lado, empresários e profissionais dizem haver necessidades prioritárias em investimentos turísticos que vão da infra-estrutura básica (transporte saúde, educação ...) à estrutura turística (transporte de superfície, hotéis, marinas, espaços de eventos ...), assim como o marketing de grande abrangência (interno e externo) e, inclusive, o esforço significativo para recuperação de posição no "ranking" mundial das cidades do Rio de Janeiro e de Salvador.

Foram apontadas pelos empresários e profissionais a necessidade de assessoria nas áreas de recursos humanos, comunicação visual, finanças, marketing, qualidade, aspectos juridicos e pesquisa de mercado, que poderiam ser melhor exploradas pelos estudiosos de Turismo. Pensa-se, no entanto, que é preciso uma análise setorial mais profunda para detalhar tais prioridades.

Os assuntos assinalados pelos empresários e profissionais como os que mais necessitam de pesquisas, cujos resultados são aplicáves à realidade turística, são os seguintes: estatísticas turísticas; informações parainvestidores; formação e treinamento de recursos humanos; qualidade aplicada à empresa turística e aos serviços oferecidos; tipos de turismo e turistas; outros inseridos na visão sustentável do Turismo. Isto mostra que eles sentem as deficiências de informações confiáveis para poder enfrentar com mais fundamento a competitividade no mercado.

Voltanto às forças globais emergentes de McIntosh, Goeldner e Ritchie (1995) e fazendo a relação com os pontos de vista dos empresários, tem-se os seguintes temas:
- turismo ambiental: ambiente como centro;

- formação e treinamento de recursos humanos: dilema recursos tecnológicos versus recursos humanos.

Ressalta-se que não será uma ação isolada que irá alterar a situação da pesquisa turística no Brasil, mas sim um conjunto de ações que pressionem as entidades de apoio e de financiamento, reafirmando a importância e os benefícios de suas colaborações para o Turismo Brasileiro. Isto em um contexto onde o Turismo apareça como uma das prioridades econômicas e políticas, e os empresários tenham uma imagem positiva e real do pesquisador turístico.

\section{Propostas para Valorização da Pesquisa e do Pesquisador Turístico}

Após essas considerações sobre a realidade e as necessidades e prioridades da pesquisa turística no Brasil, destacam-se algumas propostas que são de capital importância para que tanto a pesquisa quanto o pesquisador sejam valorizados no processo de desenvolvimento harmônico, integrado, sustentável e auto-sustentável do Turismo no Brasil. Só assim deixar-se-á a fase de improvisação e de repentinidade, e passar-se-á à fase de aplicação e utilização de estudos com base científica.

1. Atualizar continuamente a base de dados sobre informações da produção científica turística já existente ${ }^{3}$ e desenvolver outras fontes de informações sobre publicações científicas, periódicas ou não, editadas no País.

2. Disponibilizar via Internet acervos de bibliotecas de instituições de ensino superior em Turismo, a fim de estabelecer uma rede de comunicação e intercâmbio de informações.

3. Homogeneizar a metodologia de captação de dados para a produção de estatísticas, e desenvolver programas de divulgação com uma comunicação mais adequada aos diferentes segmentos interessados - pesquisador e empresário/ profissional - da área.

4. Reativar e recuperar o Centro Brasileiro de Documentação Turística (Cebitur) do Instituto Brasileiro de Turismo, como núcleo referencial da documentação especializada na área e da memória turística nacional ${ }^{4}$.

5. Divulgar, em suplementos de Turismo de grandes jornais, em revistas de informação e em periódicos informativos especializados a aplicabilidade e

\footnotetext{
3. Esse estudo foi apresentado como tese de livre docência para obtençāo de título acadêmico na especialidade "Teoria do Turismo e do Lazer", junto ao Departamento de Relaçōes Públicas, Propaganda e Turismo da ECA-USP em dezembro de 1997 (Rejowski, 1997).

4. Háprojeto de implantaçăo de um Centro de Excelênciaem Turismo, junto à Universidade de Brasília, com a proposta de em centro de documentação turística que incorporaria o acervo do Cebitur.
} 
pertinência dos resultados de pesquisa, mostrando os benefícios desta e da parceria pesquisador/empresário para o desenvolvimento e planejamento estratégico do Turismo no Brasil.

6. Estimular a realização de eventos de pequeno porte, trazendo empresários e pesquisadores para discutirem problemas da área, quebrando através de técnicas adequadas de reunião, as barreiras existentes entre ambos.

7. Incrementar pesquisas aplicadas às necessidades das empresas, para colaborar com o aumento da eficiência e eficácia das mesmas para conseguir maior competitividade no mercado internacional.

8. Apresentação dos resultados de pesquisas aos empresários e profissionais, procurando discutir sua aplicabilidade nas empresas da área.

Finalizando as propostas calcadas nas forças globais emergentes, nas opiniões dos pesquisadores e dos empresários e profissionais, chegou-se às prioridades para temas de pesquisa apresentadas a seguir.

1. Turismo Sustentável: ter o ambiente como centro de estudo mediante formas de exploração racional do espaço receptivo, preservação dos recursos naturais e culturais.

2. Novas Demandas: ter as alterações demográficas como responsáveis pelo surgimento de um novo tipo de turistas com diferentes necessidades e motivações. Adequar a infra-estrutura e a prestação de serviços especializados, especificamente para cada segmento de público (terceira idade, deficientes, jovens, famílias ...).

3. Qualidade na Prestação de Serviços: buscar a satisfação dos turistas nos equipamentos, mais primordialmente na satisfação deles em relação aos serviços turísticos. Desenvolver projetos competitivos com diferenciais que possam atrair a demanda nacional e internacional, pensando nas alianças de zonas e destinos turísticos em ofertas regionais.

4. Oferta Turística: buscar a diversidade de oferta mediante turismo marítimo e fluvial, assim como novos destinos utilizando a identidade histórica e cultural, e a revalorização de atrativos naturais e culturais.

5. Recursos Humanos: desenvolver programas de reciclagem e capacitação de recursos humanos em todos os níveis e dentro de cada segmento em particular.

6. Interação entre Turistas e Residentes: enfocar o conhecimento da cultura dos residentes para desenvolver uma relação humana mais "concreta" e para que haja harmonia e reconhecimento de valores dos dois lados.

7. Respeito ao Espaço Receptivo: propor o conhecimento de culturas diferentes e expandir o universo cognitivo do turista, tornando-o mais "compreensível" de comportamentos diferentes dos seus, mediante as informações "pré-viagens", para o que a colaboração de estudiosos quanto aos traços culturais de comportamento é essencial.

8. Turismo, Estabilidade e Segurança: ter em destaque que quanto mais sólida a moeda, mais estável o país economicamente e mais segurança no espaço turístico, maior a procura turística. A marginalidade, a pobreza, a violência são alguns importantes fatores inibidores do Turismo, que se inserem no estudo de destinos turísticos decadentes.

A pesquisa turística no próximo Milênio contribuirá para o desenvolvimento do Turismo Brasileiro, que é previsto como um dos setores econômicos importante para a balança comercial, absorção de mão-de-obra e, conseqüentemente, melhoria da qualidade da população, se tiver um papel relevante nesse processo. Para que o Turismo exerça a maximização de seus benefícios e a minimização de seus malefícios, faz-se necessário o engajamento efetivo de todos os agentes envolvidos, ou seja, dos pesquisadores, empresários, profissionais, políticos e residentes, em que o primeiro deles deverá ser o centro convergente e irradiante do processo.

\section{Referências Bibliográficas}

REJOWSKI, Mirian. 1997. Realidade das pesquisas turisticas no Brasil. Visāo de pesquisadores e profisssionais. Sāo Paulo, ECA-USP, 2v. (Tese de Livre Docência)

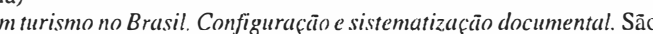

列 York: John Wilwy \& Sons.

Recebido em 5/5/98.

Aprovado em $9 / 6 / 98$ 